\title{
Editorial: Benchmarks for Undergraduate Science
}

\author{
C. C. Chancey, Editor \\ American Journal of Undergraduate Research \\ University of Northern lowa \\ Cedar Falls, lowa 50614-0150 USA
}

In a recent editorial for the journal Science ${ }^{1}$, John H. Marburger III addressed the topic of "Wanted: Better Benchmarks." Dr. Marburger is director of the Office of Science and Technology Policy, Executive Office of the President of the United States, and his discussion of how a society plans and makes policy for science is a timely topic for undergraduate science faculty.

Dr. Marburger begins by asking questions such as "How much should a nation spend on science? What kind of science? How much from private versus public sectors? Does demand for funding by potential science performers imply a shortage of funding or a surfeit of performers?" He goes on to point out that "These and related science policy questions tend to be asked and answered today in a highly visible advocacy context that makes assumptions that are deserving of closer scrutiny..."

Those of us in the college and university science community might in turn ask "How much money should a college spend on undergraduate science? What kind of science? How much from endowments versus operating budgets? Does the need for science funding imply a shortage of funds or an oversupply of science departments?" Each of these questions likely has been asked, in some form, in the last few years by our college provost or president, or by our board of

\footnotetext{
1 John H. Marburger III, "Wanted: Better Benchmarks," Science, Vol. 238 (20 May 2005) p. 1087.
}

regents or state legislature. Of course, each of us is a strong partisan for undergraduate science, but how do we make the case to a wider audience without clear benchmarks that can prompt compelling public arguments?

Marburger demonstrates the centrality of benchmark data in a discussion of the US technical workforce. The tack of his argument resonates with undergraduate science education. There are sharply differing opinions on the US's production of Bachelor's degree graduates in science. Advocates for increased production might highlight low US graduation rates in comparison with countries like China and India; critics might emphasize the limited opportunities for employment, especially in the physical sciences.

Resolving the relative importance of these and other data requires more than a local understanding. Our global marketplace requires global perspectives, even with undergraduate science education. Undergraduate science is no longer so deeply embedded in the sands of our society that the international tide doesn't lap at its boundaries.

Many individuals and several STEM organizations (notably CUR and Project Kaleidoscope) are actively involved in undergraduate science policy. Marburger's call to action to achieve better benchmarks will require a great deal of work. Let us, as undergraduate science educators, do our part to ensure that these better benchmarks integrate undergraduate science education. 